\title{
Study of the Runoff Depth and Its Processes of Eucalyptus Plantations Natural Watersheds
}

\author{
Liang Hong-wen ${ }^{1}$, Ma Qing ${ }^{1}$, Li Xiaoqiong ${ }^{1}$, Guo Jin-chuan ${ }^{2}$, Yang Jian-ji ${ }^{3}$ \\ ${ }^{1}$ College of Forestry, Guangxi University, Nanning, China \\ ${ }^{2}$ Guangxi Hydraulic Research Institute, Nanning, China \\ ${ }^{3}$ Guangxi Jingui Forestry Co. Ltd., Nanning, China
}

\section{Email address:}

lhwen59@163.com (Liang Hong-wen)

\section{To cite this article:}

Liang Hong-wen, Ma Qing, Li Xiaoqiong, Guo Jin-chuan, Yang Jian-ji. Study of the Runoff Depth and Its Processes of Eucalyptus Plantations Natural Watersheds. Science Discovery. Vol. 5, No. 3, 2017, pp. 205-209. doi: 10.11648/j.sd.20170503.18

Received: January 4, 2017; Accepted: February 3, 2017; Published: May 11, 2017

\begin{abstract}
The runoff and runoff process of Eucalyptus plantations natural watersheds were studied to provide guidance for scientific evaluation of water conservation capacities of Eucalyptus plantations, compared with the Pinus massoniana forest natural watersheds. The runoff volume of Eucalyptus plantations and P. massoniana forest natural watersheds were continuously monitored using the small watershed runoff monitoring method and the automatic data collection devices from August, 2013 to December, 2015, and effects of heavy rainfall and continuous rainfall on the runoff process were studied. Results show that the annual runoff coefficient of Eucalyptus plantations natural watershed were 0.046 , and 55.8\% lower than P. massoniana forest (0.104), with the difference being significant $(P<0.01)$. The runoff duration, time lags, maximum runoff of rainfall, and runoff depth amounts caused by a heavy rainfall process (amounting to $65.5 \mathrm{~mm}$ ) between the two kinds of forest watershed were significant different, those of Eucalyptus plantations were 8.5 h, $25 \mathrm{~min}$ and $2.69 \mathrm{~mm}$, respectively, while those of $P$. massoniana forest were $18.4 \mathrm{~h}, 55 \mathrm{~min}$ and $5.52 \mathrm{~mm}$, respectively. Eucalyptus plantations natural watershed produced only 4-days runoff, and runoff depth amounted to $3.8 \mathrm{~mm}$ with a 7 days continuous precipitation process of rainfall with $125.0 \mathrm{~mm}$, while $P$. massoniana forest produced continuously 13-days runoff, and the runoff depth was $10.1 \mathrm{~mm}$. In conclusion, water conservation capacity of Eucalyptus plantations is obviously lower than P. massoniana forest.
\end{abstract}

Keywords: Eucalyptus Plantations, Pinus massoniana Forest, Natural Watershed, Runoff Depth, Runoff Processes

\section{对桉树人工林自然集水区径流深及其径流过程的研究}

\author{
梁宏温 ${ }^{1}$, 马倩 ${ }^{1}$, 李晓琼 ${ }^{1}$, 郭晋川 ${ }^{2}$, 杨健基 ${ }^{3}$ \\ ${ }_{1}^{1}$ 广西大学林学院, 南宁, 中国 \\ ${ }^{2}$ 广西水利科学研究院, 南宁, 中国 \\ ${ }^{3}$ 广西金桂林业有限公司，南宁，中国 \\ 邮箱 \\ 1hwen59@163.com（梁宏温）
}

摘要：通过研究桉树人工林自然集水区的径流量及其径流过程, 并以马尾松林自然集水区作对照, 为科学评估桉树人 工林的水源涵养功能提供参考依据。于2013年8月-2015年12月运用小流域径流监测方法和自动采集数据, 对桉树人工 林及其相邻的马尾松林自然集水区进行径流量定位观测, 并研究连续降雨和暴雨对径流过程的影响。结果表明, 桉树 人工林自然集水区的年平均径流系数为 0.046 , 比马尾松林的 (0.104) 低 $55.8 \%$, 差异极显著 $(P<0.01)$ 。一次暴雨过 程（降水量 $65.5 \mathrm{~mm}$ ), 两种森林集水区的总径流深、径流最大值滞后于降雨峰值的时间和径流历时都存在显著差异, 桉树林的分别为 $8.5 \mathrm{~h} 、 25 \mathrm{~min}$ 和 $2.69 \mathrm{~mm}$, 马尾松林的依次为 $18.4 \mathrm{~h} 、 55 \mathrm{~min}$ 和 $5.52 \mathrm{~mm}$ 。一次连续 $7 \mathrm{~d}$ 的降雨过程（降 
水量 $125.0 \mathrm{~mm}$ ), 马尾松林自然集水区连续产生 $13 \mathrm{~d}$ 径流, 总径流深 $10.1 \mathrm{~mm}$, 而桉树人工林仅产生 $4 \mathrm{~d}$ 径流, 总径流 深3. $8 \mathrm{~mm}$ 。综上所述, 桉树人工林的水源涵养功能明显低于马尾松林。

关键词: 桉树人工林, 马尾松林, 自然集水区, 径流深, 径流过程

\section{1. 引言}

森林植被的径流特征是森林水文学研究的重要内容, 小 流域径流量及其径流系数是区域水资源评价的核心指标 [1-3]。一般认为, 森林植被具有在雨季消减洪峰和在旱季 增加产流的作用, 但森林对径流的影响在不同学者的研究中 存在较大差异 [4-6]。径流变化受所处的地形地质条件、植 被类型、流域面积和降水等诸多因素的影响。其中, 影响最 大的是区域降水量、降水强度及其降水历时 [7-10]。近期研 究表明, 森林植被对调节小流域径流的效应有所夸大, 森林 植被与径流形成的关系, 尚需要进一步研究 [11-13]。

桉树是中国南方地区的主要用材树种, 现有森林面积 $4.4 \times 10^{6} \mathrm{hm}^{2}$, 其中广西的桉树人工林面积 $2.04 \times 10^{6} \mathrm{hm}^{2}$ （第 八次森林资源清查数据）。然而桉树人工林小流域（自然集水 区）的径流特征, 目前很少报道。本文应用小流域径流监测手 段, 自动采集数据, 定位研究桉树人工林自然集水区的径流量 及其径流过程, 并以相邻近的马尾松林自然集水区作对照, 旨 为科学评估桉树人工林的水源涵养功能提供参考依据。

\section{2. 材料与方法}

\section{1. 自然条件及集水区概况}

研究区的地理位置: E $108^{\circ} 51^{\prime} 06^{\prime \prime} \sim 108^{\circ} 55^{\prime} 15^{\prime \prime}$, N $22^{\circ} 30^{\prime} 12^{\prime \prime} \sim 22^{\circ} 36^{\prime} 05^{\prime \prime}$ ，海拔 $80 \sim 160$ m。属于南亚 热带季风气候区, 全年平均气温 $21.5^{\circ} \mathrm{C}, 8$ 月平均气温 $27.3^{\circ} \mathrm{C}$, 极端最高温 $39.2^{\circ} \mathrm{C}$, 1月平均气温 $12.1^{\circ} \mathrm{C}$, 极端最低温 $-1.2^{\circ} \mathrm{C}$, 年平均降水量 $1341.8 \mathrm{~mm}$, 年平均日照 $1750.3 \mathrm{~h}$, 年平均 蒸发量 $1650.8 \mathrm{~mm}$, 年平均无霜期 $336 \mathrm{~d}$ 。地带性土壤为花 岗岩（杂有少量第四纪红土）风化发育而形成的砖红壤, 土 层厚80 100 cm; 地带性的森林植被为南亚热带常绿阔叶林, 但已不复存在。现有的森林主要是桉树 (Eucalypt) 人工林, 并保留有少量的马尾松 (Pinus massoniana) 林。
两种森林的自然集水区均位于公净水库 (隶属广西南 宁市横县新福镇管理）集雨区的西北方向，属于同一山丘 向东南方向延伸的两坡夹一沟 “ $\Lambda$ 形” 集水区, 其最高处 海拔 $156.6 \mathrm{~m}$, 坡度 $20 \sim 30^{\circ}$, 沟底较平缓, 落差为 $2 \%$ $3 \%$, 两个集水区的出口处水平距离约 $160 \mathrm{~m}$, 两者之间相 隔一条山沟及两侧山坡。

桉树人工林自然集水区面积 $3.682 \mathrm{hm}^{2}$, 现实林分为 桉树萌芽林, 是由 2005 年采伐马尾松天然林后种植桉树, 于 2010 年12月采伐, 采用伐桩萌芽, 每伐桩保留 1 株萌芽 条, 培育 $3 \mathrm{a}$ 的人工纯林; 其乔木层高 $11.6 \sim 13.5 \mathrm{~m}$, 郁 闭度 0.5 , 林木密度 1535 株/ha, 胸径 $9.8 \sim 12.4 \mathrm{~cm}$; 灌木 层高0. 5 2 $\mathrm{m}$, 平均总盖度 $13.1 \%$, 以大青 (Clerodendrum cyrtophyllum)、越南悬钩子 (Rubus cochinchinensis)、 山苍子 (Litsea cubeba) 、黄牛木（Cratoxylum cochinchinense) 、盐肤木 (Rhus chinensis) 、玉叶 金花 (Mussaenda kwangsiensis) 为优势种类; 草本层高 1. $5 \sim 2 \mathrm{~m}$, 平均总盖度 $89.4 \%$, 以五节芒为主要优势种类; 枯枝落叶层厚 $1 \sim 3 \mathrm{~cm}$, 咜量平均为 $1.02 \mathrm{t} / \mathrm{ha}$ 。

马尾松林自然集水区面积 $6.605 \mathrm{hm}^{2}$, 现实林分为自然下 种、飞子成林, 林龄 $30 \mathrm{a}$, 其乔木层组成树种除由马尾松 (595 株 $/ \mathrm{hm}^{2}$ ) 构成上层林冠外, 还有其他一些阔叶树 (655株 $/ \mathrm{hm}^{2}$ ) 构成下层林冠; 其乔木层高6. 8 $14.5 \mathrm{~m}$, 郁闭度 0.7 , 胸径 7. $4 \sim 19.4 \mathrm{~cm}$; 灌木层高0. 5 2. $5 \mathrm{~m}$, 平均总盖度 $37.8 \%$, 以桃金娘（Rhodomyrtus tomentosa）、棱枝冬青（Ilex angulata) 、红叶藤 (Rourea minor)、总状山矾 (Symplocos botryantha) 、华南毛柃 (Eurya ciliata) 为优势种类; 草本层高 $0.2 \sim 1.5 \mathrm{~m}$, 平均总盖度 $27.2 \%$, 以铁芒其 (Dicranopteris linearis) 、蔓生莠竹 (Microstegium vagans) 、五节芒 (Miscanthus floridulus) 为优势种类; 枯枝落叶层厚 $5 \sim 15 \mathrm{~cm}$, 咜量平均为 $8.47 \mathrm{t} / \mathrm{ha}$ 。

两种林地的土壤水分物理特性 (容重、孔隙度、渗透 等）也因森林植被的影响存在一些差异, 详见表 1 。

表1 两种林分集水区土壤的水分物理性质。

Table 1. Soil water-physical property of two kinds of forest watershed.

\begin{tabular}{|c|c|c|c|c|c|c|c|c|c|c|}
\hline \multirow{2}{*}{$\begin{array}{l}\text { 森林 } \\
\text { 类型 }\end{array}$} & \multirow[t]{2}{*}{ 土层 $(\mathrm{cm})$} & 土壤容重 & $\begin{array}{l}\text { 毛管孔 } \\
\text { 隙度 }\end{array}$ & $\begin{array}{l}\text { 非毛管孔 } \\
\text { 隙度 }\end{array}$ & $\begin{array}{l}\text { 总孔 } \\
\text { 隙度 }\end{array}$ & $\begin{array}{l}\text { 最大 } \\
\text { 持水量 }\end{array}$ & $\begin{array}{l}\text { 毛管 } \\
\text { 持水量 }\end{array}$ & $\begin{array}{l}\text { 最小 } \\
\text { 持水量 }\end{array}$ & 初渗系数 & 稳渗系数 \\
\hline & & $\left(\mathrm{g} / \mathrm{cm}^{3}\right)$ & $(\%)$ & $(\%)$ & $(\%)$ & $(\mathrm{mm})$ & $(\mathrm{mm})$ & $(\mathrm{mm})$ & $(\mathrm{mm} / \mathrm{min})$ & $(\mathrm{mm} / \mathrm{min})$ \\
\hline \multirow{6}{*}{$\begin{array}{l}\text { 马尾 } \\
\text { 松林 }\end{array}$} & $0 \sim 20$ & 1.18 & 36.31 & 13.47 & 49.78 & 103.30 & 83.81 & 64.10 & 15.21 & 5.28 \\
\hline & $20 \sim 40$ & 1.27 & 35.09 & 12.65 & 47.74 & 94.08 & 75.71 & 59.57 & 13.04 & 4.32 \\
\hline & $40 \sim 60$ & 1.44 & 31.45 & 11.07 & 42.52 & 85.54 & 69.85 & 52.20 & 10.40 & 3.44 \\
\hline & $60 \sim 80$ & 1.55 & 30.34 & 10.40 & 40.74 & 81.61 & 67.11 & 48.88 & 8.79 & 3.03 \\
\hline & $80 \sim 100$ & 1.64 & 28.95 & 9.56 & 38.51 & 76.74 & 63.72 & 44.77 & 5.67 & 2.35 \\
\hline & 平均 & 1.42 & 32.43 & 11.43 & 43.86 & 88.25 & 72.04 & 53.90 & 10.62 & 3.70 \\
\hline \multirow{6}{*}{$\begin{array}{l}\text { 桉树 } \\
\text { 林 }\end{array}$} & $0 \sim 20$ & 1.32 & 33.60 & 11.98 & 45.58 & 96.63 & 77.57 & 61.56 & 12.80 & 4.16 \\
\hline & $20 \sim 40$ & 1.38 & 32.13 & 12.08 & 45.21 & 91.43 & 73.95 & 57.17 & 12.22 & 3.71 \\
\hline & $40 \sim 60$ & 1.46 & 31.87 & 11.33 & 43.20 & 87.03 & 70.88 & 53.45 & 10.46 & 3.33 \\
\hline & $60 \sim 80$ & 1.56 & 30.78 & 10.66 & 41.44 & 83.17 & 68.20 & 50.19 & 8.91 & 3.01 \\
\hline & $80 \sim 100$ & 1.65 & 28.49 & 9.28 & 37.77 & 75.10 & 62.58 & 43.38 & 5.68 & 2.31 \\
\hline & 平均 & 1.47 & 31.77 & 11.07 & 42.64 & 86.67 & 70.64 & 53.15 & 10.01 & 3.30 \\
\hline
\end{tabular}




\section{2. 径流量观测}

在研究林分集水区出水口一端各修建1座三角量水堰, 量水堰出水口角度为 $90^{\circ}$, 量水堰拦水墙深入基岩 $30 \mathrm{~cm}$, 并使用防水材料; 其引水槽尺寸满足 $B>5 h 、 h / P<0.5$ 、 $h=0.06 \sim 0.65 \mathrm{~m}, \mathrm{~B}$ 为引水槽内部宽度 $(\mathrm{m}) 、 \mathrm{~h}$ 为水头高度 $(\mathrm{m}) 、 P$ 为堰口底部至引水槽底部的高度 $(\mathrm{m})$ 。于2013 年7月31日各安装一台WFX一 40 型水位计 (徐州市伟思水务 科技有限公司生产)，用来观测集水区的径流量及其径流 过程。使用YD-1003型遥测终端机（徐州市伟思水务科技 有限公司生产) 自动采集数据, 每隔 $5 \mathrm{~min}$ 记录 1 次 (水头 高度有变化时, 每隔 $1 \mathrm{~min}$ 记录 1 次）, 采集期为 2013 年 8 月 1 日0：00一-2014年7月31日23：60。采用经验公式： $\mathrm{Q}=1.343 \mathrm{~h}^{2.47}[14]$ 计算集水区的瞬时流量 $\left(\mathrm{m}^{3} / \mathrm{s}\right)$, 式中 $\mathrm{h}$ 为水头高度 $(\mathrm{m})$ 。根据径流时间 $(\mathrm{s})$ 和集水区面积 (ha) 计算出集水区的单位面积径流量 $\left(\mathrm{m}^{3} / \mathrm{ha}\right)$ 。

\section{3. 大气降雨观测}

在研究林分附近的空旷处架设JD一05型翻斗式自记 雨量计 (徐州市伟思水务科技有限公司生产) , 雨量计分 辨率为 $0.1 \mathrm{~mm}$, 用来观测每场降雨的降水量及其降水过程。 使用YD-1003型遥测终端机自动采集数据, 每隔5min记录1
次（降水量有变化时, 每隔1min记录1次）, 按每天、每 月和每年统计降雨量。

\section{3. 结果与分析}

\section{1. 研究区的大气降水状况}

研究区在 2013 年 8 月 1 日一 2015 年 12 月 31 日共有 189 天 产生降雨, 总降水量3 264.8mm, 将各月平均降水量 (图1) 累计, 获得研究区的年平均降水量为 $1341.8 \mathrm{~mm}$ 。依据《地 面气象观测规范》 [15], 对每次 (天) 的降水量按降雨等 级进行统计, 结果显示: 小雨 $(<10 \mathrm{~mm})$ 天气出现的频 率虽然最高, 达96次, 但其降水量仅为 $530.5 \mathrm{~mm}$, 占总降 水量的 $16.3 \%$; 中雨 (10 24.9 mm) 天气出现的频率较高, 达61次, 降水量为 $993.3 \mathrm{~mm}$, 占总降水量的 $30.4 \%$; 大雨 (25 49.9 mm) 和暴雨 $(50 \sim 99.9 \mathrm{~mm})$ 天气出现的频率分 别为 18 次和 12 次, 降水量依次为 $616.5 \mathrm{~mm}$ 和 $762.8 \mathrm{~mm}$, 各 占总降水量的 $18.9 \%$ 和 $23.3 \%$; 大暴雨 (100 249.9 mm) 天 气出现的频率虽然最低, 仅 2 次, 但其降水量达 $361.7 \mathrm{~mm}$, 占总降水量的 $11.1 \%$ 。

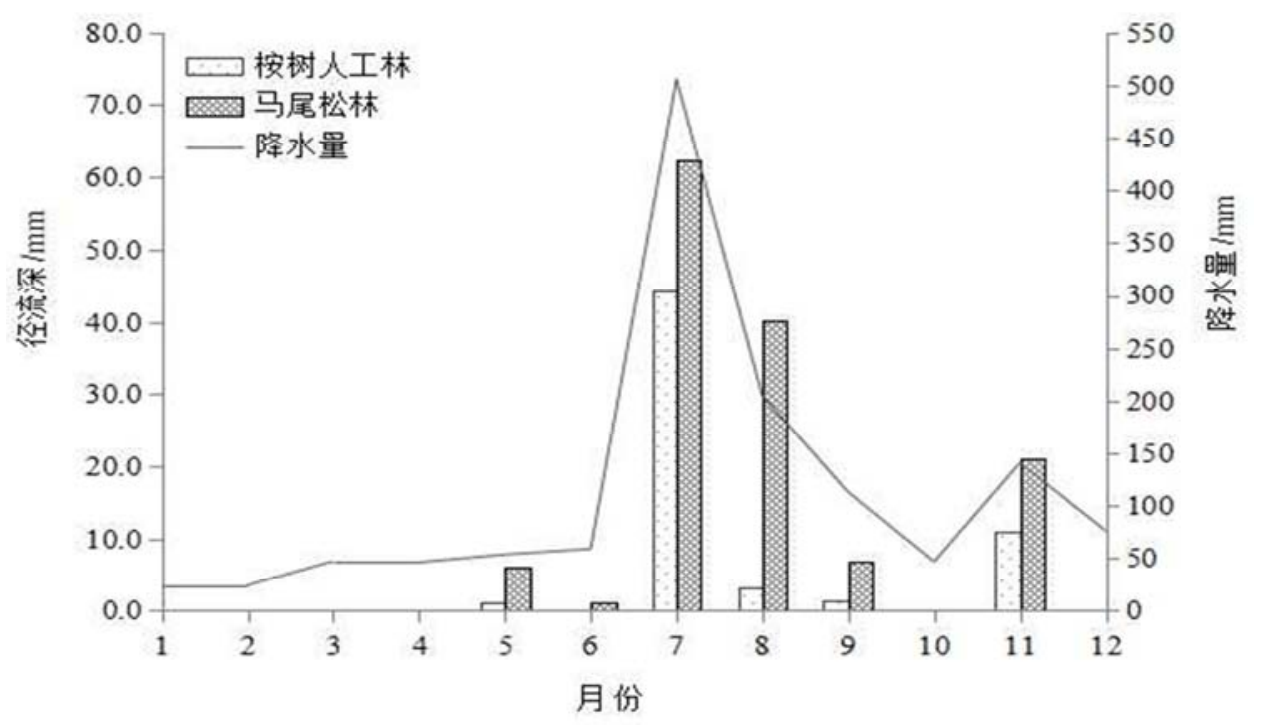

图1 两种森林集水区平均径流深的月分布。

Figure 1. The runoff depth of two kinds of forest watershed.

\section{2. 桉树人工林集水区径流深与马尾松林的比较}

将各月的平均径流深 (图1) 累计, 获得桉树人工林 自然集水区的年平均径流深为 $61.4 \mathrm{~mm}$ ，马尾松林的为 $139.3 \mathrm{~mm}$ 。两者的径流系数 (径流深占同期降水量的比 值）分别是为 0.046 和 0.104 , 前者比后者的低 $55.8 \%$, 两者之间差异极显著 $(P<0.01)$ 。由图1看出, 两种森林 集水区在监测年份的1 4月和10月都没有发生径流, 桉树 人工林集水区在 6 月和 12 月也没有产生径流，其余各月的 径流深均比马尾松林的低, 又以 8 月的表现最为突出,
桉树人工林集水区的径流深只有 $3.1 \mathrm{~mm}$, 马尾松林的高 达 $40.3 \mathrm{~mm}$, 两者相差十分悬殊。

\section{3. 一次降暴雨的径流过程分析}

图2显示，2013年9月4日02：30开始下雨，10：55和 11: 50 分别出现降雨峰值, 其 5 min内的降水量分别为 2.9 $\mathrm{mm}$ 和 $4.5 \mathrm{~mm}$, 至 $23: 55$ 的日累计降水量达 $65.5 \mathrm{~mm}$, 属于 暴雨天气。由图2看出, 桉树人工林集水区量水堰口开始 出现水流的时间为 11: 30 (累积降水量达到 $32.5 \mathrm{~mm}$ ), 径流滞后于降雨的时间为 $9.0 \mathrm{~h} ; 12: 15$ 累积降水量达到 
$50.5 \mathrm{~mm}$ 时, 水头高度达到最大值 $0.23 \mathrm{~m}$, 洪峰出现, 瞬 时流量 $0.0356 \mathrm{~m}^{3} / \mathrm{s}$, 径流最大值滞后于降雨峰值的时间 为 $25 \mathrm{~min}$; 至 $20: 00$ 水头高度低至 $0.001 \mathrm{~m}$, 径流结束, 径流历时 $8.5 \mathrm{~h}$ 。马尾松林集水区量水堰口开始出现水流 的时间为5: 30 (累积降水量达到 $10.5 \mathrm{~mm}$ ), 径流滞后于 降雨的时间为 $3.0 \mathrm{~h} ; 12$ : 45累积降水量达到 $58.0 \mathrm{~mm}$ 时, 水头高度达到最大值 $0.29 \mathrm{~m}$, 洪峰出现, 瞬时流量 0.0631 $\mathrm{m}^{3} / \mathrm{s}$, 径流最大值滞后于降雨峰值的时间为 $55 \mathrm{~min}$; 至 23 :
55 水头高度低至 $0.001 \mathrm{~m}$, 径流结束, 径流历时 $18.4 \mathrm{~h}$ 。 该次暴雨过程, 桉树人工林集水区的径流历时比马尾松林 的短 $9.9 \mathrm{~h}$ 、径流最大值滞后于降雨峰值的时间比马尾松 林的提前 $0.5 \mathrm{~h}$ 、径流的水头高度最大值比马尾松林的浅 $0.06 \mathrm{~m}$ 。根据图2计算获得这一次暴雨产生的单位面积径 流深, 桉树人工林集水区的为 $2.69 \mathrm{~mm}$, 马尾松林的为 5.52 $\mathrm{mm}$, 前者的径流深只是后者的 $48.7 \%$, 两者相差很明显。

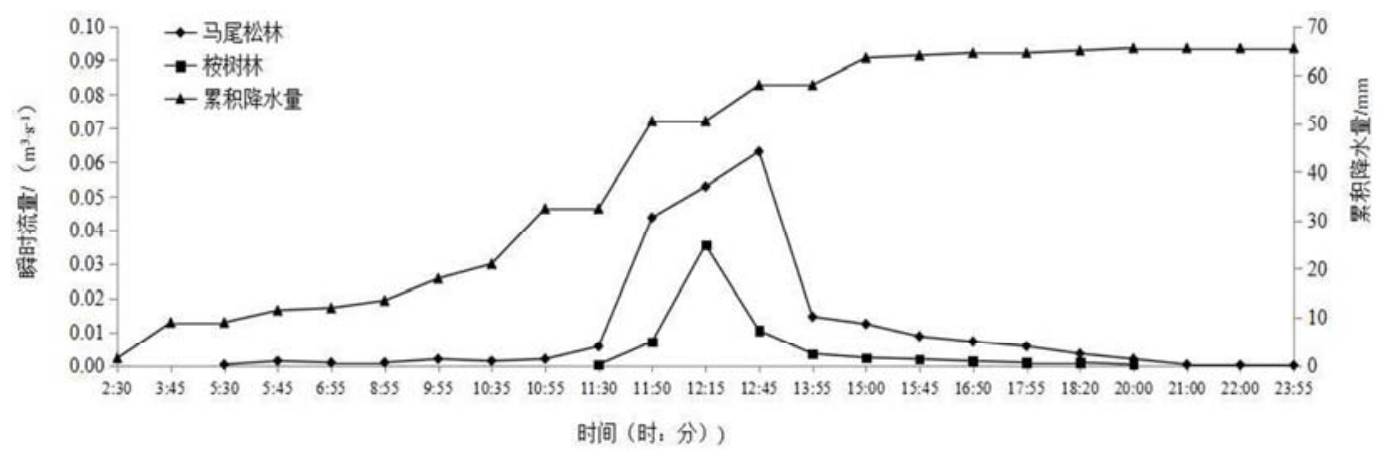

图2 两种森林集水区瞬时流量随降水量的变化曲线。

Figure 2. The instantaneous flow curve with rainfall of two kinds of forest watershed.

\section{4. 连续降雨的径流过程分析}

图3是2013年9月1日一-13日的降雨过程及两种森林集 水区径流量的逐日分布曲线。由图3看出，期间发生 1 次暴 雨 $(65.5 \mathrm{~mm}) 、 1$ 次大雨 $(27.5 \mathrm{~mm}) 、 2$ 次中雨 $(14.0 \mathrm{~mm}$ 和 $11.0 \mathrm{~mm})$ 和 3 次小雨 $(3.0 \mathrm{~mm} 、 2.5 \mathrm{~mm}$ 和 $1.5 \mathrm{~mm})$, 共 $7 \mathrm{~d}$ 发生降雨, 总降水量 $125.0 \mathrm{~mm}$ 。图3显示, 桉树人工林 集水区只有在降大雨和暴雨时才产生径流, 且径流延续的
时间很短, 其9月 1 日（大雨）产生的径流在当日就完成, 9月4日（暴雨）产生的径流，在9月6日降中雨的补充下维 持了 $3 \mathrm{~d}$, 期间只产生 $4 \mathrm{~d}$ 径流, 总径流深仅 $3.8 \mathrm{~mm}$; 马尾 松林集水区在这 7 天产生的径流量一直高于桉树人工林, 其径流过程在 3 次小雨和 2 次中雨的补充下, 由 1 次大雨和 1 次暴雨产生的径流一直延续到 9 月 13 日，期间共发生 $13 \mathrm{~d}$ 径流, 总径流深达 $10.1 \mathrm{~mm}$, 是桉树人工林的 2.66 倍。

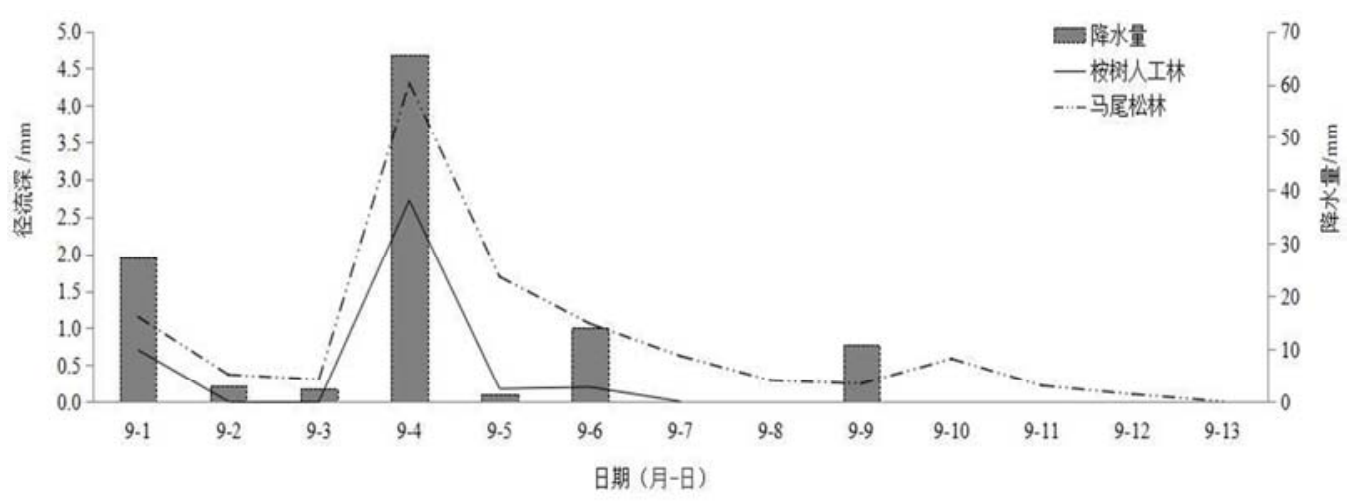

图3 两种森林集水区径流深随降水量分布曲线。

Figure 3. Runoff depth distribution curve with rainfall of two kinds of forest watershed.

\section{4. 讨论与结论}

森林植被的水文功能既表现在降雨产流量上，也表现 在降雨径流过程上, 森林植被的调蓄作用在发生暴雨洪水 时更为明显 [16]。本研究选择地形相似且距离相近的两种 森林集水区开展小流域径流观测试验。结果显示，桉树人 工林集水区的年均径流深和径流系数分别为 $61.4 \mathrm{~mm}$ 和 0.046 , 马尾松林的分别为 $139.3 \mathrm{~mm}$ 和 0.104 , 两者相差 十分明显。其原因主要在于这两种森林群落的林下地被
物组成及其土壤水分物理特性明显不同 (表1)。其中: 马尾松林的林下植被较为稀疏, 其灌木层高 $0.5 \sim 2.5 \mathrm{~m}$ 、 平均总盖度 $37.8 \%$, 草本层高 $0.5 \sim 1.5 \mathrm{~m}$ 、平均总盖度 $27.2 \%$, 但枯枝落叶层较厚、达 $5 \sim 15 \mathrm{~cm}$ (平均贮量 8.47 $\mathrm{t} / \mathrm{hm}^{2}$ ), 而且其土壤孔隙结构较好, 穿透林冠的降水, 在经过林地表面时很容易随土壤入渗, 再经土壤不透水 层渗出至汇流沟一起形成径流。桉树人工林的草本植被 覆盖度很大, 平均总盖度达 $89.4 \%$, 且以五节芒为主要优 势种类（重要值52.92）, 由于五节芒生长茂盛、密集分 
布、根系发达, 能有效地阻挡了林内降雨的径流产生。 桉树人工林自然集水区的径流量较低的原因是否还与 桉树生长较快, 光合作用耗水量较大, 吸取土壤中的水 分过多, 因土壤干燥而大量地吸收来自径流中的水分等 有关, 还需要进一步研究。

小流域径流的延长或滞后, 除了受到植被覆盖特性的 影响外, 在很大程度上与降水特性、前期土壤水分含量、 地形和土壤等多种因素影响有关, 尤其是当降水过程不同 时, 会产生不同的滞后效应 [13, 17]。一次暴雨(降水量 $65.5 \mathrm{~mm})$ 的径流过程表明, 桉树人工林的径流历时较短 (仅8.5 h) 、径流最大值滞后于降雨峰值的时间提前 (仅 $25 \mathrm{~min}$ ) 和径流水头峰值较浅 (仅 $0.23 \mathrm{~m}$ ), 马尾松林的 较长 (达 $18.4 \mathrm{~h}$ ), 延后 (达5 $5 \mathrm{~min}$ ) 和较深 (达0.29 m); 一次连续7 d 降雨 (降水量累计 $125.0 \mathrm{~mm}$ ) 的径流过程显 示, 桉树人工林只产生 $4 \mathrm{~d}$ 径流、径流深 $3.8 \mathrm{~mm}$, 马尾 松林则连续产生 $13 \mathrm{~d}$ 径流、径流深 $10.1 \mathrm{~mm}$ 。由此表明, 桉树人工林的水源涵养功能明显弱于马尾松林。

本文对桉树人工林自然集水区的径流深及其径流过 程进行了初步研究, 尚未对其生态系统不同效应层次的森 林持留降水量及其再分配进行深入研究。今后应该从不同 效应层次持留森林降水量及其再分配, 针对不同雨量条件 和土壤前期含水量前提下, 根据土壤水分的收支状况来研 究桉树人工林集水区的径流特征及其径流过程, 进一步揭 示桉树人工林的水源涵养机制, 为桉树人工林的可持续经 营和管理提供科学依据。

\section{致谢}

本论文研究得到中国人民共和国水利部公益性行业 科研专项（201301044）的经费资助。

\section{参考文献}

[1] CALDER I R. Forests and water-ensuring forest benefits outweigh water costs $[\mathrm{J}]$. Forest Ecology and Management, 2007, 251 (1/2) :110-120.

[2] WANG Y H, YU P T, FEGER K, et al. Annual runoff and evapotranspiration of forestlands and non-forestlands in selected basins of the Loess Plateau of China [J]. Ecohydrology, 2011, 4(2) : 277-287.

[3] JOSTA G, SCHUMEC H, HAGERC H, et al. A hillslope scale comparison of tree species influence on soil moisture dynamics and runoff processes during intense rainfal1[J]. Journal of Hydrology, 2012, 420:112-124.

[4] 王金叶, 李海防, 段文军, 等. 漓江上游典型森林群落内 外降雨特征研究 [J]. 水土保持研究, 2012, 19 (1) : 56-59.

[5] 段文军, 李海防, 王金叶, 等. 漓江上游典型森林植被对 降水径流的调节作用 [J] . 生态学报, 2015, 35 (3) :663-669.

［6］李耀明, 王玉杰, 储小院, 等. 降雨因子对缙云山地区典 型森林植被类型地表径流的影响 $[\mathrm{J}]$. 水土保持研究, 2009, 16 (4) :244-249.

[7] CHININO E, BONET A, BELlOT J, et al. Effects of 30 year old allepo pine plantations on runoff, soil erosion, and plant diversity in a semiarid landscape in south eastern Spine $[J]$. Catena, 2006, 65 (2) : 19-29.

[8] 索安宁, 熊友才, 王天明, 等. 黄土高原子午岭森林破碎 化对流域水文过程的影响 [J]。林业科学, 2007, 43 (6) : 14 -19 .

［9］范世香, 程银才, 高 雁, 等. 考虑森林植被影响的小流域 降雨径流模型 $[J]$. 生态学报, 2008, 28(5):2372-2379.

[10] HUMANN M, SCHULER G, MULLER C, et al. Identification of runoff processes the impact of different forest types and soil properties on runoff formation and floods [J]. Journal of Hydrology, 2011, 409 ( $3-4)$ : $637-649$.

[11] NEARY D G, ICE G G, JACKSON C R . Linkages between forest soils and water quality and quantity $[\mathrm{J}]$. Forest Ecology and Management, 2009, 258 (10) : 2269-2281.

[12] 周光益, 陈步峰, 曾庆波, 等. 海南岛热带山地雨林短期 水量平衡及主要养分的地球化学循环研究 $[J]$. 生态学报, 1996, 16(1)：28-32.

[13] 王金叶，李海防，段文军，等.漓江上游森林小流域径流 过程及其影响因素 $[J]$. 林业科学, 2013,49(6) : 149-153.

[14] 欧阳竹, 孙波, 刘健. 陆地生态系统水环境观测规范 [M]. 北 京: 中国环境科学出版社, 2007: 104-106.

[15] 中央气象局. 地面气象观测规范 $[\mathrm{M}]$. 北京: 气象出版社, 1979:32-34.

[16] 魏晓华, 李文华, 周国逸, 等. 森林与径流的一致性与复 杂性 $[\mathrm{J}]$. 自然资源学报, 2005, 20(5) : 127-136.

[17] 王小明，周本智，钟绍柱，等．不同降雨条件下天然次生 林水文过程动态分析 $[\mathrm{J}]$. 南京林业大学学报 (自然科学 版）, 2010, 36（6）:57-60. 